\title{
Doppler Sonographic Changes of Portal Vein in Chronic Hepatitis C Versus Normal Healthy Population
}

\author{
Iqra Ramzan S.Noor ul Hassan Hafiza Maryam Tauseef Memona Nazir Zara Jabeen \\ University Institute of Radiological Sciences and Medical Imaging Technology, The University of Lahore, \\ Pakistan
}

\begin{abstract}
Background: Hepatitis $\mathrm{C}$ is a liver disease caused by hepatitis $\mathrm{c}$ virus (HCV is RNA virus). The virus can cause both acute and chronic infection, ranging in severity from a mild illness lasting a few weeks to a serious, lifelong illness ${ }^{1}$. The hepatitis $\mathrm{c}$ virus is blood born virus and is most common modes of infections are through unsafe injection practices; inadequate sterilization of medical equipments; and transfusion of unscreened blood and blood products. ${ }^{2}$ Objective: To evaluate Doppler Sonographic changes of portal vein in chronic hepatitis $\mathrm{C}$ versus normal healthy population.Methodology: Different types of Doppler ultrasound machines Toshiba, Aloka and Esote equipped with 3.5-5 MHZ curve linear multi-frequency transducer was used to scan the liver and portal venous system.Results: In this study, 40 patients were scanned, 20 of them were HCV positive and 20 were normal subjects. out of $20 \mathrm{HCV}$ positive patients, 13 were male and 7 were female, while in normal subjects 11 were male and 9 were female The mean portal vein flow velocity in HCV positive patient was $11.1015 \pm 2.6470$ which is reduced as compared to normal subjects $20.4400 \pm 4.37558$. The portal vein flow direction in normal subjects was hepatopetal flow while in HCV positive patients flow was hepatofugal flow in 12 patients and hepatopetal in 8 patients.Conclusion: We conclude from our results that HCV positive patient population shows various changes in liver size, echo texture, blood flow characteristics and some other associated features like ascites and collateral formation as a result of portal hypertension.
\end{abstract}

Keywords: portal vein, Doppler ultrasound, chronic hepatitis

DOI: $10.7176 / \mathrm{JHMN} / 77-03$

Publication date:July $31^{\text {st }} 2020$

\section{Introduction}

Portal vein is formed by the confluence of splenic and superior mesenteric veins. It supplies around $70 \%$ of incoming blood volume to liver ${ }^{3}$. The portal trunk divides in the liver into two branches: the left portal vein branch and the right portal vein branch. The right portal vein branch divides secondarily into two branches: the right anterior portal vein feeding segments V and VIII and the right posterior vein feeding segments VI and VII. Any deviation from this anatomy is considered an anatomical variant ${ }^{4}$ Conventional ultrasound is a valuable tool in the assessment of liver parenchyma and detection of liver lesions. Ultrasound (US) has a major role in the diagnosis and management of chronic liver diseases by providing diagnostic and prognostic information, as well as detecting complications such as hepatocellular carcinoma and portal hypertension. ${ }^{5}$.

Hepatitis $\mathrm{C}$ is a viral disease with a high potential for chronicity (as infection with the hepatitis $\mathrm{C}$ virus persisting for more than six months). Chronic HCV infection may result in fibrosis, cirrhosis and /or hepatocellular carcinoma. It is estimated that about $3 \%$ of the world's population is infected with $\mathrm{HCV}$ and that 3 million people are infected each year. Eighty percent of new cases will become chronic carriers. Of these patients, $10 \%$ to $20 \%$ will develop the serious complications of cirrhosis and $1 \%$ to $5 \%$ will develop hepatocellular carcinoma ${ }^{6}$.

With the help of Doppler ultrasound not only real-time flow but the direction of flow can also be detected. Pulsed Doppler provides additional information about flow. It is used to find the velocity of flow, characteristics of flow and the nature of vascular bed in which flow occur ${ }^{7}$. Doppler ultrasound (US) has been accepted as the gold standard in assessing the direction of flow in the portal venous system. Hepatofugal flow can be demonstrated on angiography, Doppler ultrasonography, magnetic resonance imaging, and / or CT. Doppler ultrasound however tends to be best modality at quantifying this abnormality ${ }^{8}$.

When pulsed Doppler ultrasound is used to examine the portal vein, a monophasic wave pattern is shown, with variations in velocity caused by respiration. A value of $15 \mathrm{~cm} / \mathrm{sec}$ is considered to be the best cut-off point in tests to detect portal hypertension, with high sensitivity and specificity of $88 \%$ and $96 \%$, respectively 9

\section{Method:}

Sonographic scanning of patients in my work was part of routine. I have started collecting data from June 2015 to August 2015.A case control study was performed in the Parkview clinic of Prof. Dr. Muhammad Nawaz Anjum and Al-Sheikh Medical Centre, Lahore. The study was done on 40 people, subjects with no exclusion on gender / age. This was include 20 known cases of chronic hepatitis $\mathrm{C}$ with evidence of variable degrees of cirrhosis on grey scale ultrasound and 20 of normal subject.

Lab test was performed for diagnosis of hepatitis c virus: 
HCV RNA test Qualitative; was used to distinguish between a current or past infection, it was reported as positive if any HCV viral RNA was found otherwise report were negative.Different types of Doppler ultrasound machines Toshiba, Aloka and Esote equipped with 3.5-5 MHZ curve linear multi-frequency transducer was used to scan the liver and portal venous system.

Using intercostal approach, Color Doppler was used to evaluate the direction of the flow in the main portal vein i.e. hepatopetal /hepatofugal and the peak venous velocity (PVV) with subjects in the supine position during suspended inspiration. Flow velocity was measured from the hilar segment with subjects in the supine position and during inspiration. For measurement of the velocity, the angle of insonation was always less than 60 degree. A series of Doppler indices of hepatic vascularity including, portal vein diameter, portal vein velocity, portal vein flow direction, presence of ascites and collateral vessels and any other sonographic findings was evaluated.

\section{Results}

In this study, 40 patients were scanned, 20 of them were HCV positive and 20 were normal subjects. Table-I Maximum patient age of 40 patients was 75 years and minimum age was 14 years. Their range was 61 with mean

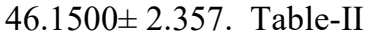

From $20 \mathrm{HCV}$ positive patients, 13 were male and 7 were female, while in normal subjects 11 were male and 9 were female. Table -III

The parenchymal echo texture of normal subjects was "Fine" while HCV positive patients were mildly coarse in 3 patients, coarse in 12 and highly coarse in 5 patients respectively. Table-IV

The maximum liver span of $\mathrm{HCV}$ positive patients was $17.70 \mathrm{~cm}$ and the minimum was $10.60 \mathrm{~cm}$ with the mean of $15.055 \pm 2.03844$ while in normal subject, maximum liver span was $17.00 \mathrm{~cm}$ and the minimum was $12.10 \mathrm{~cm}$ with the mean of $14.9750 \pm 1.24176$. Table- V

The Maximum portal vein diameter in HCV positive patients was $13 \mathrm{~mm}$ and minimum was $9 \mathrm{~mm}$ and their mean was $11.6950 \pm 1.03490$ while in normal subjects maximum diameter was $12 \mathrm{~mm}$ and minimum was $9 \mathrm{~mm}$ with mean $9.8500 \pm 0.81273$. Table-VI.

The maximum portal vein velocity in HCV positive patients $14.21 \mathrm{~cm} / \mathrm{s}$ and minimum was $4.70 \mathrm{~cm} / \mathrm{s}$ and their mean were $11.1015 \pm 2.6470$ while in normal subjects maximum velocity was $28.50 \mathrm{~cm} / \mathrm{s}$ and minimum was 14.00 with mean $20.4400 \pm 4.37558$. Table-VII

The portal vein flow direction in normal subjects was hepatopetal flow while in HCV positive patients flow was Hepatofugal flow in 12 patients and hepatopetal in 8 patients. Table-VIII

Ascities, Collaterals were absent in normal subjects while in HCV positive patients present in 12 patients and absent in 8 patients. Table-IX

\section{TABLES}

Table-I: Frequency Table

\begin{tabular}{|l|r|r|r|r|}
\hline & Frequency & Percent & Valid Percent & Cumulative Percent \\
\hline Abnormal & 20 & 50.0 & 50.0 & 50.0 \\
Normal & 20 & 50.0 & 50.0 & 100.0 \\
Total & 40 & 100.0 & 100.0 & \\
\hline
\end{tabular}

Table-II: Descriptive Statistics

\begin{tabular}{|l|r|r|r|r|r|r|r|}
\hline & \multicolumn{1}{|c|}{$\mathrm{N}$} & \multicolumn{1}{c|}{ Range } & Minimum & \multicolumn{1}{c|}{ Maximum } & \multicolumn{2}{|c|}{ Mean } & Std. Deviation \\
\cline { 2 - 7 } & Statistic & Statistic & Statistic & Statistic & Statistic & \multicolumn{1}{c|}{ Std. Error } & \multicolumn{1}{c|}{ Statistic } \\
\hline Age & 40 & 61.00 & 14.00 & 75.00 & 46.1500 & 2.35708 & 14.90749 \\
& 40 & & & & & & \\
\hline
\end{tabular}

Table-III: Gender * HCV Cross tabulation

\begin{tabular}{|ll|r|r|r|}
\hline & & \multicolumn{2}{|c|}{ HCV } & \multicolumn{2}{|c|}{ Total } \\
\cline { 3 - 4 } & & Abnormal & Normal & \\
\hline \multirow{2}{*}{ Gender } & Female & 7 & 9 & 16 \\
Total & Male & 13 & 11 & 24 \\
\hline
\end{tabular}


Table -IV: Liver Parenchymal echo texture * HCV Cross tabulation

\begin{tabular}{|ll|r|r|r|}
\hline & & \multicolumn{2}{|c|}{ HCV } & \multirow{2}{*}{ Total } \\
\cline { 2 - 4 } & & Abnormal & Normal & \\
\hline & Coarse & 12 & 0 & 12 \\
Liver Parenchymal echo texture & Fine & 0 & 20 & 20 \\
& Highly Coarse & 5 & 0 & 5 \\
& Mildly Coarse & 3 & 0 & 3 \\
Total & & 20 & 20 \\
\hline
\end{tabular}

Table -V: Liver Span

\begin{tabular}{|c|c|c|c|c|c|c|}
\hline $\mathrm{HCV}$ & Mean & $\mathrm{N}$ & Std. Deviation & Minimum & Maximum & $\%$ of Total $\mathrm{N}$ \\
\hline $\begin{array}{l}\text { Abnormal } \\
\text { Normal } \\
\text { Total }\end{array}$ & $\begin{array}{l}15.0550 \\
14.9750 \\
15.0150\end{array}$ & $\begin{array}{l}20 \\
20 \\
40\end{array}$ & $\begin{array}{l}2.03844 \\
1.24176 \\
1.66649\end{array}$ & $\begin{array}{l}10.60 \\
12.10 \\
10.60\end{array}$ & $\begin{array}{l}17.70 \\
17.00 \\
17.70\end{array}$ & $\begin{array}{r}50.0 \% \\
50.0 \% \\
100.0 \%\end{array}$ \\
\hline
\end{tabular}

Table-VI: Portal vein diameter ( $\mathrm{mm})$

\begin{tabular}{|l|r|r|r|r|r|r|}
\hline HCV & \multicolumn{1}{|c|}{ Mean } & $\mathrm{N}$ & Std. Deviation & \multicolumn{1}{c|}{ Minimum } & Maximum & $\%$ of Total N \\
\hline Abnormal & 11.6950 & 20 & 1.03490 & 9.00 & 13.00 & $50.0 \%$ \\
Normal & 9.8500 & 20 & .81273 & 9.00 & 12.00 & $50.0 \%$ \\
Total & 10.7725 & 40 & 1.31012 & 9.00 & 13.00 & $100.0 \%$ \\
\hline
\end{tabular}

Table-VII: Portal vein velocity $(\mathrm{cm} / \mathrm{s})$

\begin{tabular}{|l|r|r|r|r|r|r|}
\hline HCV & Mean & N & Std. Deviation & Minimum & Maximum & \% of Total N \\
\hline Abnormal & 11.1015 & 20 & 2.64709 & 4.70 & 14.21 & $50.0 \%$ \\
Normal & 20.4400 & 20 & 4.37558 & 14.00 & 28.50 & $50.0 \%$ \\
Total & 15.7708 & 40 & 5.92469 & 4.70 & 28.50 & $100.0 \%$ \\
\hline
\end{tabular}

Table-VIII: Portal vein flow direction * HCV Cross tabulation

\begin{tabular}{|ll|r|r|r|}
\hline \multirow{2}{*}{} & & \multicolumn{2}{|c|}{ HCV } & \multirow{2}{*}{ Total } \\
\cline { 3 - 4 } & Abnormal & Normal & \\
\hline \multirow{2}{*}{ Portal vein flow direction } & Hepatofugal & 12 & 0 & 12 \\
Total & Hepatopetal & 8 & 20 & 28 \\
\hline
\end{tabular}

Table-IX: Ascities, collaterals * HCV Cross tabulation

\begin{tabular}{|ll|r|r|r|}
\hline & & \multicolumn{2}{|c|}{ TCV } & \multirow{2}{*}{ Total } \\
\cline { 2 - 4 } & & Abnormal & Normal & \\
\hline \multirow{2}{*}{ Ascities, collaterals } & Absent & 8 & 20 & 28 \\
Total & Present & 12 & 0 & 20 \\
& & 20 & 20 \\
& & & 40 \\
\hline
\end{tabular}

\section{Discussion}

In our study we found that the liver span was greater in HCV positive patients as compared to the normal healthy population. The previous studies however reported as liver span shrunken in cirrhotic patients with the passage of time. The reason of greater liver span might be due to early cirrhotic changes in most of the patient population in our study.

Certain hemodynamic disruptions in liver vessels go along with chronic hepatic diseases. These alterations are generally the result rather than the cause of hepatic dysfunction and structural changes. Resistance and pulsatility indices, Flow velocity of portal vein and hepatic arteries are parameters susceptible to pathologic and morphologic changes. These parameters can reliably be evaluated by Doppler sonography. Many reports confirmed the clinical usefulness of this technique in the diagnosis of portal hypertension and liver cirrhosis. 
Alterations of liver hemodynamic resulting from inflammation at the tissue level are detectable on Doppler sonography. This non-invasive technique is helpful for assessment of the degree of liver inflammation and the stage of fibrosis, and it should be used to follow the progression of HCV. Doppler sonography has high diagnostic value for cirrhosis. ${ }^{10}$

The normal portal vein demonstrates an undulating hepatopetal flow. ${ }^{11} \mathrm{We}$ found hepatopetal flow in $100 \%$ of the normal population. Mean portal venous velocity is reported to be approximately 15 to $18 \mathrm{~cm} / \mathrm{sec} .{ }^{11}$ the value which we found in our study was $20.4 \mathrm{~cm} / \mathrm{sec}$, which is almost similar to the reported value. As portal hypertension develops, the flow in the portal vein loses its undulatory pattern and becomes progressively flattened. As the severity of portal hypertension increases, flow becomes biphasic and finally hepatofugal. ${ }^{11}$ In our patient population we also noted the same finding with $12 / 20=60 \%$ cases having hepatofugal flow pattern in the portal vein.All patients in normal group were found to have 'Fine liver echo texture' with absent ascities and collaterals with hepatopetal flow. Liver echo texture in HCV positive patients was mildly coarse in 3/20 (15\%); coarse in $12 / 20(60 \%)$ and highly coarse in $5 / 20(25 \%)$ patients. $60 \%$ patients presented with ascites, collaterals and hepatogugal flow. The portal vein diameter increases in HCV positive patients as compared to normal subjects. ${ }^{12}$ we also found the same trend in our. The Portal venous velocity in HCV positive patients was reduced .Our results are in accordance with already reported results of previous studies. ${ }^{10,11 \text {, and } 12}$

\section{Conclusion}

We conclude from our results that HCV positive patient population shows various changes in liver size, echo texture, blood flow characteristics and some other associated features like ascites and collateral formation as a result of portal hypertension.

\section{References}

1. G.R Foster R.D Goldin and H.C Thomas (1998), Chronic Hepatitis C Virus Infection Causes a Significant Reduction in Quality of Life in the Absence of Cirrhosis, Hepatology, 27:209-212.

2. Myron A.Pozniak and Paul 1 Allen (2014), clinical Doppler Ultrasound, Elesvier limited, pg no 152.

3. Myron A. Pozniak and Paul 1 Allen, (2014), Clinical Doppler Ultrasound, Elesvier limited, pg no 152.

4. Guest Editors David C. Madoff M.D. Thierry de Baere M.D, 2008 Jun, Portal Vein Normal Anatomy and Variants: Implication for Liver Surgery and Portal Vein Embolization, Semin Intervent Radio, 25(2): 86-9

5 .J. F. Gerstenmaier and R. N. Gibson, 2014 Aug, Ultrasound in chronic liver disease, Insights Imaging, 5(4): $441-455$.

6 .Haroldo Luis Oliva Gomes RochaI; AngélicaLemos Debs DinizII; Valéria Ferreira de Almeida e BorgesI; Frederico Chaves SalomãoII, Jan./Mar. 2012, Assessment of portal venous index as a non-invasive method for diagnosing liver fibrosis in patients with chronic hepatitis C, Arq. Gastroenterol, vol.49

7. Rumack CM, et al, 2005, Diagnostic Ultrasound Third Edition, vol 1. P. 1019-1020.

8 .Puneet Mittal,1,* Ranjana Gupta,1 Gaurav Mittal,2 and Vishal Kalia,2011 Dec, Association Between Portal Vein Color Doppler Findings and the Severity of Disease in Cirrhotic Patients With Portal Hypertension, Iran J Radio, 8(4): 211-217.

9 .Jorge Leão*, Marianna Brock, Márcia Castilho, André Scariot, Ana Scariot and Wornei Braga, Feb 12012 , Non-Invasive Assessment of Fibrosis Using Color Doppler Ultrasound in Patients with Hepatitis C Virus in the Amazon Rainforest, Brazil, Am J Trop Med Hyg, 86(2): 273-279.

10.Alpay Haktanir, MD, Birsen Songül Cihan, MD, Çetin Çelenk, MD, S, ener Cihan, MD,2005,Value of Doppler Sonography in Assessing the Progression of Chronic Viral Hepatitis and in the Diagnosis and Grading of Cirrhosis, J Ultrasound Med; 24:311-321.

11..Anish Subedee, Benu Lohani, Shashi Sharma, CORRELATION OF PORTAL VEIN PULSATILITY PATTERN AND SEVERITY OF LIVER DISEASE IN PATIENTS WITH CIRRHOSIS AND PORTAL HYPERTENSION, Journal of Nobel Medical College, Vol. 2, No.1 Issue 3.

12..Aminu Usman Umer, Nasiru Tahir, Sani Garko (2015) Sub Saharan African Ultrasound Determination of Portal Vein Diameter in Adult Patients with Chronic Liver Disease in North-Eastern Nigeria, Journel of Medicine, volume:2 ,Issue:2, pg :57-63. 